\title{
Ensino de inglês na aviação brasileira: a emergência de um campo de conhecimento científico no Brasil (1990-2009)
}

\author{
Teaching English in Brazilian Aviation: \\ the emergence of a field of scientific knowledge in Brazil (1990-2009)
}

\author{
Luciane Maris Urvaneja Nazareth* \\ Adolfo Ignacio Calderón**
}

Resumo: Neste artigo abordamos a avaliação do ensino de língua estrangeira, buscando traçar o chamado estado da questão do ensino de língua inglesa voltada para a aviação, com ênfase na segurança de voo. Após uma discussão teórica sobre a avaliação no ensino e das principais abordagens do ensino das línguas estrangeiras, apresentamos as tendências em termos de pesquisas sobre a avaliação do ensino de inglês focada na área da aviação, resultante de um levantamento bibliográfico entre os anos 1990 e 2009, sobre os estudos que fazem parte do Banco de Teses e Dissertações da Capes a respeito da avaliação do ensino de inglês na área da aviação, mostrando a fragilidade existente nesta área de estudos, especificamente no que tange aos aspectos da segurança de voo.

Palavras-chave: Avaliação do ensino. Avaliação do currículo. Língua inglesa para aviação.

Abstract: This article deals with the assessment of foreign language teaching, aiming to trace the method in which the teaching of English focused on aviation functions, with emphasis on flight security. After a theoretical discussion of the evaluation of learning and the main approaches to teaching foreign languages, we present trends in research on the evaluation of English teaching focused on the area of aviation, resulting from a literature survey from 1990 to 2009 of the studies that are part of the CAPES archive of academic theses and dissertations concerning the evaluation of English teaching in the area of aviation. Our research shows the weakness of this area of study, specifically concerning flight safety aspects.

Keywords: Teaching assessment. Curriculum evaluation. English language for aviation.

\section{Introdução}

Este artigo foca-se na avaliação do ensino de língua estrangeira buscando traçar o chamado estado da questão do ensino de língua inglesa voltada para a aviação. Conforme Therrien e Nóbrega-Therrien (2004), o estudo do estado da questão consiste num rigoroso levantamento bibliográfico para contextualizar como se encontra um determinado tema ou objeto de pesquisa, no atual estado da ciência ao seu alcance.

\footnotetext{
* Mestre em Educação pela Pontifícia Universidade Católica de Campinas e Docente de Língua Inglesa da Academia da Força Aérea Email: <lurvaneja@uol.com.br>.

** Doutor em Ciências Sociais pela Pontifícia Universidade Católica de São Paulo com Pós-Doutorado em Ciências da Educação pela Universidade de Coimbra. Professor do Programa de Mestrado em Educação da Pontifícia Universidade Católica de Campinas. E-mail: <adolfo.ignacio@puc-campinas.edu.br>.
} 
Após uma discussão teórica sobre a avaliação do ensino e de uma análise histórica sobre as principais abordagens do ensino das línguas estrangeiras a partir das obras de Chagas (1979), Didática especial de línguas modernas e do livro Approaches and methods in language teaching, (Richards; Rodgers 1986), apresentamos as tendências em termos de pesquisas sobre a avaliação do ensino de inglês focada na área da aviação, resultante de um levantamento bibliográfico entre os anos 1990 e 2009, sobre os estudos que fazem parte do Banco de Teses e Dissertações da Capes na área da avaliação do ensino de inglês na área da aviação, mostrando a fragilidade existente nesta área de estudos, especificamente no que tange aos aspectos da segurança de voo.

O domínio da língua inglesa no âmbito operacional a respeito da aviação é uma questão fundamental em termos de segurança. São vários os acidentes com aeronaves tanto em solo quanto em voo que ocorreram por falha de comunicação ou mal-entendidos entre torre de controle e pilotos. $\mathrm{O}$ acidente mais recente ocorrido por falha de compreensão entre piloto e torre foi em 29 de setembro de 2006, entre um avião da empresa GOL e um jato Legacy 600. De acordo com reportagem exibida pela Folha de São Paulo, em sua versão digital no dia 25 de maio de 2010, houve um mal entendido entre a torre de controle e os pilotos do Legacy.

Ao receberem da torre de Brasília a ordem "manter", piloto e co-piloto entenderam que deveriam manter as diretrizes indicadas em São José dos Campos de seguindo a rota até Manaus a 37 mil pés de altitude. 'Houve uma falha de comunicação também entre o controlador da torre na serra do Cachimbo e o piloto. Uma questão de inglês e de medida, o comprimento: 2.600 pés ou 2.600 metros de pista, então o piloto teve que assumir a menor das duas, na dúvida. (FOLHA DE SÃO PAULO, 2010).
Ao analisarmos outros acidentes ocorridos, listados em ordem cronológica desde a década de 1970, desta vez pela versão digital do jornal O Estado de São Paulo, constatamos que dos 112 acidentes listados, oito ocorreram por falha de comunicação entre piloto e torre, entre estes aquele ocorrido em Tenerife.

27 de março de 1977: Durante o vôo o Boeing 747 da K.L.M. ele recebeu ordens para desviar seu vôo para Tenerife, Ilhas Canárias, pois ocorrera um atentado a bomba num dos terminais de Grã-Canária, seu aeroporto de destino o avião pousou com segurança. Na mesma pista um Boeing 747 da Pan Am, era abastecido, o mesmo se passara com este vôo, ele havia sido desviado para Tenerife. Quando a situação no aeroporto de Grã-Canária se tranqüilizou, os voos voltaram a ser liberados. Em virtude de falhas na comunicação, devido ao poucos conhecimentos de inglês do pessoal da torre e outros problemas técnicos, houve algum mal-entendido, e o capitão da KLM entendeu que poderia decolar. O piloto do Boeing da Pan Am tentou evitar a catástrofe realizando uma manobra para sair da pista, mas já era tarde. O 747 da KLM cortou a lateral do jato da Pan Am a uma velocidade de 250 quilômetros por hora, provocando uma enorme explosão que matou 583 pessoas que ocupavam as aeronaves. As equipes de resgate levaram nove horas para apagar o incêndio (O ESTADO DE SÃO PAULO, 2010)

Convém registrar que até o presente momento, início da segunda década de 2000, o acidente de Tenerife é considerado o pior envolvendo aeronaves em virtude da grande quantidade de mortes ocorridas. Quando analisamos os demais acidentes descritos no site do jornal O Estado de São Paulo podemos apurar que pelo menos $50 \%$ dos casos foram provocados por falha humana (erro do piloto, incorreção no plano de vôo, 
problemas no controle de tráfego, carga armazenada de maneira inadequada, falha de manutenção, erros de comunicação).

Este trabalho, então, se insere nas preocupações teóricas em torno da necessidade do aprimoramento do ensino de inglês para aqueles que atuam na aviação brasileira. Conforme o Manual de Procedimentos da Agência Nacional de Aviação Civil (2009), que versa sobre a verificação do cumprimento dos requisitos de proficiência linguística de pilotos de transporte aéreo e da aviação geral, o piloto deve ser capaz de compreender e comunicar-se em língua inglesa em situações atípicas, como no caso de uma pane ou problema com a aeronave.

Por meio deste artigo poderemos perceber que a temática 'ensino de inglês na área de aviação', no momento, ainda conta com poucos estudos preocupados com a língua inglesa como fator de segurança de voo. Os estudos retratam que, apesar de alguns profissionais terem alguma fluência em língua inglesa, o que sabem, muitas vezes não é o suficiente para resolver situações de risco (ANDRADE 2003; GALLO 2006; MONTEIRO 2009). Este artigo busca auxiliar no avanço de estudos nesta área, tanto para a comunidade acadêmico-científica como também para a segurança nacional.

\section{A respeito da avaliação do ensino}

A avaliação recebe, na atualidade, um espaço de destaque entre as discussões na área acadêmica. Ela deixou de ser um simples documento que aponta sucessos e fracassos, para ser parte importante do processo de ensino. Hoje, o processo avaliatório requer do professor não só preparo, mas também capacidade de percepção, utilizando-a como ferramenta mediadora na construção do currículo e no alcance dos objetivos. O processo de aprendizagem é complexo e nele intervêm inúmeros fatores, sendo o currículo o parâmetro referencial, norteador das práticas educacionais.

$\mathrm{O}$ que se entende afinal por avaliação do ensino? Para responder esta questão poderíamos utilizar conceitos desenvolvidos por inúmeros autores. No entanto, optamos por adotar a definição realizada por um dos pioneiros do Currículo e da avaliação da aprendizagem, Tyler (1974), considerado o pai da avaliação educacional, para quem:

o processo de avaliação consiste essencialmente em determinar em que medida os objetivos educacionais estão sendo realmente alcançados pelo programa do currículo de ensino. [...] a avaliação é o processo mediante o qual se determina o grau em que as mudanças de comportamento estão realmente ocorrendo. (p.99)

Até o início da década de 1930, o foco da avaliação era examinar a quantidade de conteúdo que havia sido absorvida e que habilidades haviam sido dominadas. Tyler (1974) nos chama a atenção para todos os processos de aprendizagem que devem ser considerados durante o processo avaliativo, para que possamos avaliar nosso aluno dentro de um todo e não apenas em situações estanques. Só assim saberemos se as mudanças pretendidas estão realmente acontecendo.

Sendo assim, para que a avaliação do currículo seja mais consistente precisamos analisar o crescimento do aluno de uma forma global, não só por meio dos tópicos apreciados em aula, mas também seu desenvolvimento no decorrer daquele curso. Estas avaliações, por sua vez, devem estar ao alcance daqueles que elaboram o currículo, para que o curso possa sempre ser aprimorado. Uma única avaliação ao final do processo pode não nos fornecer dados o suficiente para que possamos aprimorar o currículo. 
Em se tratando do currículo de ensino, as primeiras discussões sobre como se pode desenvolvê-lo foram feitas por Bobbitt em 1918 em sua obra "O currículo". O autor nos mostra a necessidade de sabermos o que fazer e como fazer para que o indivíduo possa ser preparado primordialmente para uma vida prática (Bobbitt, 2004, p.43). Em 1949, quando era docente na universidade de Chicago, Tyler escreve "Princípios básicos de currículo e ensino”. A obra identifica algumas questões básicas que nortearam o desenvolvimento do currículo. Os autores, de maneira global, sugerem um programa de estudos usado como referência básica para o desenvolvimento do currículo e instrução.

Que objetivos educacionais deve a escola procurar atingir?

Que experiências educacionais podem ser oferecidas que tenham probabilidade de alcançar esses propósitos?

Como organizar de maneira eficiente essas experiências?

Como podemos ter certeza que esses objetivos estão sendo alcançados?

Podemos então perceber que o currículo é de um plano de ensino que envolve a formulação de objetivos, as relações entre objetivos e conteúdos, a seleção e organização dos procedimentos metodológicos e os procedimentos de avaliação, sendo parte da ênfase no documento escrito - currículo formal, e parte na prática escolar - o currículo real ou em ação.

Em sua obra Tyler (1974) pontua a necessidade do estudo da língua inglesa por meio da literatura. No caso da disciplina em questão, o autor pondera que, ao ter conhecimento de uma língua, extrapolamos a aprendizagem da língua per se e elevamos o aluno "além dos conhecimentos, habilidades e hábitos, pois envolvem modos de pensar, interpretação crítica, reações emocionais, interesses [...]” (p.26). Estas habilidades vão ao encontro das necessidades de fluência em comunicação que os pilotos devem possuir, e que, por sua vez, são delineadas pelos objetivos, que irão levar-nos ao "comportamento desejado".

O objetivo principal seria a "aptidão de analisar o desenvolvimento lógico e a exposição de idéias” (op. cit. p.26). Sendo assim, o estudo da língua inglesa tem uma função apreciativa. Aquele que tem conhecimento da língua inglesa é capaz de "reagir significativamente e apreciar criticamente a forma e o conteúdo.” (op. cit. p.26).

$\mathrm{O}$ autor ainda sugere que habilidades e hábitos, na prática da língua inglesa, envolvem uma forma de pensar, interpretar criticamente, reagir emocionalmente e expressar interesses. Enquanto Bobbitt (2004) nos chama a atenção para os "erros específicos, deficiências ou formas de desenvolvimento apreendido [...] por falta de conhecimento de Línguas Estrangeiras.” (p.243).

Para asseguramos esta aprendizagem efetiva é que lançamos mão das avaliações durante o período de aprendizagem. Ela está inserida em todas as práticas da sociedade, nós a fazemos a todo o momento em nosso dia a dia, ao refletirmos sobre nossas escolhas. No contexto da educação seu papel, durante décadas, tem sido o de atribuir valores (notas) com vistas à promoção ou reprovação do aluno.

Contudo deve-se registrar que essa perspectiva classificatória por meio de testes é parte do processo para que possamos averiguar os conhecimentos que o aluno possui. Para Tyler (1974), “os testes com lápis e papel são úteis para analisar e tratar eficientemente vários tipos de problemas verbais, de vocabulário, leitura e outros gêneros de habilidades e aptidões” (p.100). Ao juntarmos a estes as entrevistas e a observação de situações, hábitos e aptidões operacionais, o autor 
poderá então, ao avaliar, fazer um diagnóstico daqueles objetivos que eram pretendidos no início do processo, e a avaliação passará de cunho classificatório a diagnóstico. Desta maneira, ao trabalhar de forma contínua os conteúdos, poderá perceber ao longo do período letivo, a evolução de seus alunos, podendo cuidar melhor a elaboração e aplicação das avaliações.

Durante o período escolar, ao tomarmos como base a Constituição Federal de 1988, todo brasileiro entre os 4 e os 17 anos deve freqüentar a escola. Ao levarmos em conta os 13 anos de escolaridade obrigatória podemos inferir que uma pessoa passa por inúmeros processos avaliativos contidos nos regimentos escolares. Neste cenário, as avaliações são consideradas obrigatórias, uma vez que é por meio delas que os professores têm o feedback dos objetivos atingidos. Luckesi (1999) argumenta que "nosso exercício pedagógico escolar é atravessado mais por uma pedagogia do exame que por uma pedagogia do ensino/ aprendizagem" (p.18). Os alunos dedicam-se aos estudos "não porque os conteúdos sejam importantes, significativos e prazerosos de serem aprendidos, mas sim porque estão ameaçados por uma prova” (op. cit. p.19)

Ainda de acordo com Luckesi (1999), em muitas situações a avaliação acaba-se tornando um instrumento de domínio, por meio do qual se cobra simplesmente conteúdos memorizados de maneira mecânica sem qualquer significado para o aluno, quando na verdade seu papel seria "determinar em que medida os objetos educacionais estão sendo realmente alcançados pelo programa do currículo de ensino.” (p. 99)

O processo avaliatório envolve três tipos de avaliação: diagnóstica, formativa e somativa. Segundo Stern (1996, p.47), a avaliação diagnóstica permite ao professor conferir quais são os conhecimentos prévios que o aluno possui, a avaliação formativa é aquela realizada durante todo o processo de aprendizagem como base para verificação dos objetivos pretendidos e por fim a avaliação somativa determina o valor quantitativo do que foi aprendido.

Em se tratando da avaliação do ensino de uma língua estrangeira, normalmente procura-se verificar em que etapa do processo de aprendizagem se encontra o aluno, para que a partir do domínio que ele possui, possamos traçar os caminhos do ensino. Para Luckesi (1999, p.34) esta etapa da avaliação "teria a função de possibilitar uma nova tomada de decisão sobre um objetivo avaliado”. Para darmos segmento ao que foi assimilado o autor sugere que

a avaliação do aproveitamento escolar seja praticada com uma atribuição de qualidade aos resultados de aprendizagem dos educandos, tendo por base seus aspectos essenciais e, como objetivo final, uma tomada de decisão que direcione o aprendizado e, consequentemente, o desenvolvimento do educando (p.95)

É esse aspecto qualitativo da avaliação o caminho apresentado por Luckesi (1999) para que o professor possa se afastar da avaliação simplesmente somativa e classificatória a qual ainda está preso. Sendo assim, o professor deve

coletar, analisar e sintetizar as manifestações das condutas [...] produzindo uma configuração do efetivamente aprendido, atribuir qualidade a essa configuração da aprendizagem de acordo com padrões preestabelecidos e a partir dessa qualificação tomar uma decisão sobre as condutas docente e discente. (op. cit. p.95)

Já Para Sacristán (2000), a avaliação mostra sua importância ao atuar como "modeladora da prática curricular" vinculada à política curricular, ao tipo de tarefas nas 
quais se expressa o currículo e o professorado, escolhendo conteúdos ou planejando atividades (grifo do autor)." (p.311). Neste sentido, a avaliação pode ser o molde para ajustarmos o programa curricular.

Enquanto formativa a avaliação tem seu maior mérito quando pode auxiliar também o aluno a observar seu comportamento durante a aprendizagem. Estar ciente do seu aproveitamento é fundamental. A partir do momento que o aluno tem a chance de também verificá-lo e mensurá-lo, ele terá então uma idéia mais clara dos objetivos ainda não alcançados por ele. Traldi (1984), por sua vez, defende a avaliação como "parte integrante do desenvolvimento curricular, fazendo-se desde a 'fixação' dos objetivos, 'permanecendo' durante a dinâmica processual e indo além dos resultados.” (p.49). Com base nessa autora, pode-se afirmar que ao adotar um processo avaliativo voltado para a formação poderá ser possível observar cada ponto previsto no currículo e questionar, no decorrer do caminho, se as necessidades e objetivos estão determinados de maneira coerente com o que buscamos e se alguma mudança pode ser feita.

Por sua vez, Tyler (1974) nos mostra que avaliar implica obter evidências sobre a mudança de comportamento gerada pelo ensino a partir do currículo. Sabemos, porém que mudar um comportamento não é uma tarefa fácil. O professor terá que rever suas práticas avaliativas e transformar seus preceitos normativos em formativos. É preciso que compreenda que o aluno é quem vai nos mostrar nosso ponto de partida e de chegada. Para o autor, ao utilizarmos esta concepção de avaliação podemos observar dois aspectos importantes -

uma apreciação na fase inicial e outras mais tarde, para identificar as mudanças que estejam se processando [...] sem saber quais eram as condições dos estudantes no início não é possível determinar em que medida houve modificações. (op. cit. p.99)

Por fim, para termos certeza que as mudanças foram realmente adquiridas, devemos dar aos nossos alunos a oportunidade de mostrar esse comportamento em situações em que possam expressá-los. Desta forma fecharemos o ciclo avaliativo proposto pelo autor.

\section{Avaliação e o ensino de línguas estrangeiras}

Richards e Rodgers (1986) apontam uma estimativa de que atualmente $60 \%$ da população mundial seja bilíngue ou multillíngue. Este número indica que o multlinguismo não é mais uma exceção e sim uma constante em nossos tempos. Mas falar um ou mais idiomas não é um fato exclusivo dos dias atuais. Desde o império romano, onde a língua estrangeira era o latim, as pessoas percebem a necessidade de falar um segundo ou até um terceiro idioma.

Buscando atender esta demanda, cada vez mais era necessário desenvolver e aprimorar técnicas para o ensino de língua estrangeira. Sendo assim houve, especialmente no último século, uma proliferação de métodos e abordagens de ensino de línguas. Enquanto para alguns esta é uma preocupação comum, para outros, esta grande variedade de métodos, esta constante mudança pode confundir mais do que auxiliar, pois em muitos casos, o método não é suficientemente claro para quem o pratica. Podemos então concluir que falar em ensino de língua estrangeira, principalmente das línguas dominantes como o inglês, espanhol, alemão, italiano e francês, é falar em métodos.

O que uma pesquisa histórica do ensino de língua estrangeira nos revela é que sempre estivemos a procura de um método ideal para ensinar idiomas. À medida que 
o status do latim diminuía, em virtude das mudanças políticas na Europa, o idioma foi, aos poucos, se tornando uma disciplina "ocasional” no currículo escolar, mas seu modelo de ensino - análise da gramática e do vocabulário - foi o modelo que predominou na Europa do século XVII ao século XIX. Neste período o ensino de gramática era rigoroso. Os alunos aprendiam as declinações e conjugações, tradução e escreviam sentenças isoladas na língua-alvo. As línguas "modernas" - francês, italiano e inglês - que entraram para o currículo escolar a partir do século XVIII eram ensinadas por meio dos mesmos procedimentos usados para o latim.

Esta abordagem foi denominada Método da Gramática e Tradução (Grammar Translation Method ou GTM). O GTM foi importante na Europa aproximadamente de 1840 a 1940 e seu objetivo principal estava focado na leitura e na disciplina mental. O vocabulário era ensinado por meio de listas bilíngues de palavras, estudo do dicionário e memorização, sempre restrito ao texto lido em aula. $\mathrm{O}$ aluno era submetido a muitos testes e estes eram meticulosos. A partir da metade do século XIX, a oposição ao GMT começou a crescer na Europa. Essa oposição foi denominada Movimento Reformista e se fortaleceu a medida que a necessidade da fluência oral aumentava na Europa. Aliados aos princípios do ensino da língua nativa, resultaram no que ficou conhecido como o Método Direto. Um dos defensores mais notórios deste método foi Lambert Sauveur (1826 - 1907). Ele usava intensivamente a interação oral na língua-alvo durante as aulas.

Além de Sauveur, outros autores defendiam que a língua estrangeira poderia ser ensinada sem qualquer auxílio da língua nativa se o significado fosse transmitido diretamente por meio de demonstração. Os princípios naturais de aprendizagem foram a base do Método Direto. Essa abordagem também é conhecida como o Método de Berlitz, devido ao grande sucesso comercial da franquia fundada por Maximilliam Berlitz. Na prática, este método defendia os seguintes princípios: as aulas eram lecionadas exclusivamente em inglês; apenas frases do cotidiano eram usadas; a progressão era gradual, para consolidar a habilidade oral; uso de perguntas e respostas entre alunos e professores em aulas intensivas; a gramática era ensinada indutivamente; os novos tópicos eram apresentados oralmente e o vocabulário era ensinado por meio de gestos, objetos e fotos. A ênfase era na correção gramatical e oral.

Por volta de 1920, o uso desta abordagem em escolas não comerciais entrou em declínio e acentuou-se com um estudo publicado nos Estados Unidos denominado O Relatório Coleman em 1923 que declarava ser impraticável o ensino de conversação devido ao pouco tempo das aulas, a pouca habilidade dos professores e a irrelevância da conversação para o aluno americano comum. Este estudo apontava para o ensino de leitura como algo mais viável.

Nas décadas de 1920 e 1930 os linguistas aplicados, liderados pelo britânico Henry Sweet propuseram princípios metodológicos mais sólidos que aqueles do Método Direto. Estes princípios foram a base para outros dois métodos a Abordagem Oral (ou Método Situacional) e o Método Audiolingual, que foram desenvolvidos por linguistas aplicados britânicos entre as décadas de 1930 e 1960. Teve impacto por um longo tempo e ajudou a moldar muitos livros-texto de cursos de inglês. Os lingüistas buscavam uma abordagem oral com base científica mais sólida que aquela do Método Direto. O resultado foi um estudo sistemático dos princípios que poderiam ser aplicados à seleção e organização do conteúdo de um curso de línguas. Um dos primeiros aspectos deste método foi o controle de vocabulário. Por meio de um estudo, Harold Palmer concluiu que existiam 
2000 palavras que ocorriam frequentemente em textos e que, portanto, o conhecimento deste vocabulário seria de grande auxílio para o aluno. Esta descoberta teria um grande impacto nas décadas seguintes.

Paralelo ao interesse no vocabulário havia também o interesse no conteúdo gramatical. As principais estruturas gramaticais do inglês foram classificadas em padrões de frases que ajudavam a internalizar as regras estruturais das frases em inglês. Embora usasse procedimentos orais, este método não deve ser confundido com o Método Direto, pois estava mais fundamentado na teoria linguística.

As principais características desta abordagem eram: a língua deve ser apresentada oralmente antes que o aluno veja a forma escrita; a aula deve ser dada na língua-alvo; os tópicos devem ser apresentados em contexto; os procedimentos de escolha de vocabulário devem ser respeitados; leitura e escrita só devem ser apresentados quando o aluno já tiver uma base gramatical e lexical suficiente.

Já a história do Método Audiolingual data do Relatório Coleman. Sob a influência deste estudo foram surgindo as primeiras idéias que resultariam neste novo método. Este começo do audiolingualismo foi fortemente impulsionado pela entrada dos Estados Unidos na Segunda Guerra Mundial.

O exército americano necessitava de pessoas fluentes em alemão, francês, italiano, chinês e japonês para trabalharem como intérpretes, decodificadores e tradutores. Era necessário, então, desenvolver um treinamento para as pessoas que ocupariam estes postos. Por isso este método também foi denominado The Army Method (Método do Exército) e durou apenas dois anos, mas despertou considerável interesse na comunidade acadêmica. Entretanto, como exigia longas horas de contato entre alunos e língua-alvo, não pôde ser aproveitado no sistema de ensino americano, mas convenceu os linguistas da eficiência de um curso de línguas com longas horas e ênfase na modalidade oral. O processo avaliativo enfatizava as quatro habilidades em testes rígidos de compreensão e minúcias da língua alvo. Sendo assim, o audiolingualismo defendia o treinamento auditivo em primeiro lugar, seguido de prática de pronúncia, fala, leitura e escrita.

Em 1957, devido à necessidade de os Estados Unidos entrarem na corrida espacial, o método Audiolingual buscou algumas idéias do "Método do Exército", além dos princípios estruturais de Fries e insights da psicologia behavioristas. Destas três fontes Método do Exército, estruturalismo e behaviorismo - surgiu o método audiolingual, que ao final dos anos 1960 apresentou claros sinais de esgotamento. Ficava cada vez mais evidente era necessária uma abordagem que levasse em conta a criatividade do falante e Noam Chomsky, em 1957, antecipa essa necessidade em seu livro - Syntatic Structures.

Outro fator que impulsionou mudanças no ensino de língua estrangeira foi a crescente interdependência entre os países europeus devido ao surgimento do Mercado Comum Europeu. Com base em um documento preliminar, preparado pelo linguista britânico D. A. Wilkins, surgiu na Europa uma proposta de ensino de línguas que, ao invés de descrever a estrutura da língua por meio de gramática e vocabulário, descrevia o sistema de significados que estava por trás dos usos comunicativos da língua. Wilkins descreveu dois tipos de significados: categorias nocionais (tempo, sequência, quantidade, frequência) e categorias funcionais (pedido, negação, reclamação, oferta).

A Abordagem Comunicativa ou Ensino Comunicativo segue os seguintes passos: os diálogos baseiam-se em funções comunicativas e não devem ser memorizados; a contextualização é uma premissa básica; 
para aprender uma língua é preciso aprender a comunicar-se; qualquer recurso que ajude os alunos é bem-vinda; os alunos devem ser encorajados a comunicar-se desde o início; o uso criterioso da língua nativa é aceitável quando necessário; leitura e escrita são apresentadas desde a primeira aula.

Em meados da década de 1980 passava a onda inicial de entusiasmo com o Método Comunicativo. Esta abordagem começava a ser vista com um olhar mais crítico. Foram levantadas questões, tais como: o método pode ser aplicado em todos os níveis de um curso de línguas? Ele serve tanto para cursos de segunda língua, como para cursos de língua estrangeira? A gramática deve ser revisada ou totalmente abandonada? É adequado para professores não nativos? Como usar este método em cursos onde os alunos têm testes tradicionais de gramática?

Os métodos descritos até aqui podem ser considerados os mais populares do século XX. Além do impacto que causaram em suas épocas, mantiveram sua popularidade e serviram de referência por um considerável período de tempo. Na verdade muitas de suas práticas ainda podem ser encontradas nos cursos de línguas até hoje como, por exemplo, as listas de vocabulário (GTM) e o ensino de categorias funcionais (comunicativismo). As abordagens que veremos a seguir não obtiveram tanto sucesso quanto as cinco já vistas, embora tenham gozado de alguma popularidade em suas épocas e uma ou outra de suas práticas ainda possa ser observada em cursos de línguas. Dentre dessas abordagens, destacamos dois métodos:

Total Physical Response (TPR) Baseia-se na coordenação entre discurso e ação. Em uma típica aula de inglês por meio do TPR o professor usa comandos como wash your face, brush your teeth, draw a rectangle, para ensinar estruturas e vocabulário. Esta técnica ainda é usada para ensinar ações e também comandos do imperativo nos estágios iniciais dos cursos de línguas. Entretanto, sua aplicabilidade aos estágios mais avançados da conversação sempre foi questionada.

Outro método a ser destacado é The Silent Way (Método Silencioso) - Método desenvolvido por Caleb Gattegno. O professor inicia a aula apontando para palavras cuja tonicidade e entonação ele queira ensinar, e os alunos deverão tentar produzir enunciados com as palavras ensinadas. O termo Silencioso do nome desta abordagem vem desta busca pela indução, da aprendizagem sem o uso de explicações ou comandos verbais por parte do professor. As premissas deste método são sucintamente representadas por Benjamim Franklin: "Tell me and I forget / teach me and I remember / involve me and I learn."

Ao analisarmos as metodologias podemos perceber que às vezes elas levam em conta não só o estudo, mas também as condições em que a aprendizagem acontece. Todos os outros aqui citados colocam o professor em uma posição de modelo a ser imitado, a não ser no Método Comunicativo, no qual o professor é mediador no processo de aprendizagem. $\mathrm{O}$ aluno, por sua vez, passa de mero aprendiz passivo, apenas recebendo informações, a pessoa ativa no processo, buscando sempre autonomia e independência no uso da língua estrangeira.

Acreditamos, enfim, que vários fatores se unem para que a aprendizagem de uma língua estrangeira aconteça, mas nada pode ser mais representativo do que querer aprender. $\mathrm{O}$ aluno deve ter um objetivo que o impulsiona, independente do método escolhido, e para que esta motivação não se perca o aluno deve ser consciente de que ele é parte fundamental para que a aprendizagem/ aquisição aconteça. 


\section{O ensino de inglês na aviação}

Para tentar aproximar-nos à realidade da produção científica sobre o ensino de inglês na área da aviação, realizamos um levantamento bibliográfico das dissertações e teses produzidas entre os anos 1990 e 2009, que constam no Banco de Teses e Dissertações da Capes na área da Avaliação da Aprendizagem. As palavras de busca definidas foram: avaliação do ensino, avaliação da aprendizagem, língua estrangeira, ensino de língua inglesa, ensino de inglês para aviação. O material encontrado, 161 teses e dissertações, foi processado, categorizado e distribuído em seis tabelas.

Tabela 1 - Áreas de concentração das teses de doutorado e dissertações de mestrado produzidas no Brasil entre 1990 e 2009 - avaliação de ensino de língua inglesa.

\begin{tabular}{l|c|c}
\hline Área & Quantidade & Percentual \\
\hline Educação Superior & 57 & $35,40 \%$ \\
\hline Educação Básica & 47 & $30,19 \%$ \\
\hline Institutos de Idiomas & 23 & $14,28 \%$ \\
\hline Softwares & 19 & $11,80 \%$ \\
\hline Inglês para aviação & 7 & $4,34 \%$ \\
\hline Material Didático & 6 & $3,72 \%$ \\
\hline Imigração X Aquisição & 1 & $0,62 \%$ \\
\hline Exames de Proficiência & 1 & $0,62 \%$ \\
\hline Total & 161 & $100 \%$ \\
\hline
\end{tabular}

Na Tabela I, pode-se constatar que a ênfase predominante da produção científica está no estudo da avaliação em língua inglesa na educação superior, totalizando 35,40\% dos estudos. Em seguida vêm os estudos referentes à Educação Básica totalizando $30,19 \%$. As avaliações em institutos de idiomas totalizam consideráveis $14,28 \%$, e a preocupação com avaliações de softwares somam $11,80 \%$. Os trabalhos sobre inglês para aviação têm uma projeção de 4,34\%, o que não diminui a importância dos assuntos, ao contrário, nos mostra que há muito a ser explorado nesta área. Os estudos a respeito dos materiais didáticos, por sua vez, totalizam 3,72\%. Por fim, pesquisas sobre aquisição e imigração e exames de proficiência aparecem com $0,62 \%$ de estudos na área.

Tabela 2 - Teses de doutorado e dissertações de mestrado produzidas no Brasil entre 1990 e 2009 sobre ensino-aprendizagem e avaliação em língua inglesa no Ensino Superior.

\begin{tabular}{l|c|c}
\hline Área & Quantidade & Percentual \\
\hline Formação de professores & 18 & $31,57 \%$ \\
\hline Avaliação & 11 & $19,29 \%$ \\
\hline $\begin{array}{l}\text { Leitura, escrita, audição } \\
\text { e fala }\end{array}$ & 9 & $15,78 \%$ \\
\hline Ensino-aprendizagem & 7 & $12,29 \%$ \\
\hline $\begin{array}{l}\text { Aquisição de língua } \\
\text { Inglesa }\end{array}$ & 7 & $12,29 \%$ \\
\hline Inglês instrumental & 5 & $8,78 \%$ \\
\hline Total & 57 & $100 \%$ \\
\hline
\end{tabular}

Na Tabela ${ }^{\circ}$ II, fizemos um recorte dos estudos produzidos na área da Educação Superior. Pode-se constatar uma preocupação predominante com estudos referentes à formação de professores 31,57\%. O foco de grande parte das pesquisas concentra-se na preocupação da qualidade da formação que recebem esses futuros profissionais, especialmente no que concerne ao grau de proficiência destes professores. Em segundo lugar estão as pesquisas voltadas para a avaliação em língua inglesa que somam 19,29\% e a temática dos trabalhos é em torno da qualidade da avaliação em língua inglesa desde as séries iniciais até os exames vestibulares e também em avaliações realizadas nos cursos de formação de professores de língua estrangeira. Quanto ao desenvolvimento das habilidades (leitura, escrita, oralidade e audição) estas somam $15,78 \%$ do total. São estudos que discorrem, na sua maioria, sobre situações de sala de aula enquanto os alunos têm 
contato com a habilidade em questão. Os pesquisadores analisam, de maneira geral, como os professores lidam com o ensino de inglês como língua estrangeira, suas técnicas avaliativas, e atuação em sala de aula para o desenvolvimento da habilidade. Em seguida temos $12,29 \%$ dos trabalhos focados em ensino aprendizagem de língua inglesa. Grande parte dos trabalhos versa sobre o modo como o material didático utilizado nas aulas de Inglês, as motivações e estratégias utilizadas pelos professores. Totalizando também $12,29 \%$ das pesquisas, temos 'aquisição de língua inglesa’. Estes trabalhos baseiamse, em grande parte, nas teorias de Stephen Krashen, lingüista conhecido pela Teoria de Aquisição de Segunda Língua e pela abordagem natural no ensino-aprendizagem de língua estrangeira, enquanto outros versam sobre a aquisição vocabular. Fechando esta tabela temos os estudos sobre inglês instrumental (como a própria palavra sugere, é o estudo da língua inglesa com fins específicos. Está ligado à área da leitura e busca capacitar o aluno para ler e compreender textos com uma temática específica). Estes somam $8,78 \%$ dos estudos e tecem discussões a respeito do ensino de inglês nos cursos de administração, turismo e informática.

Tabela 3 - Teses de doutorado e dissertações de mestrado produzidas no Brasil entre 1990 e 2009 sobre ensino, aprendizagem e avaliação em língua inglesa na Educação Básica.

\begin{tabular}{l|c|c}
\hline Área & Quantidade & Percentual \\
\hline Ensino -aprendizagem & 20 & $42,55 \%$ \\
\hline Avaliação & 11 & $23,40 \%$ \\
\hline $\begin{array}{l}\text { Leitura, escrita, } \\
\text { audição e fala }\end{array}$ & 7 & $14,89 \%$ \\
\hline Aquisição & 4 & $8,51 \%$ \\
\hline Material didático & 3 & $6,40 \%$ \\
\hline Proficiência & 2 & $4,25 \%$ \\
\hline Total & 47 & $100 \%$ \\
\hline
\end{tabular}

Na Tabela $n^{\circ}$ III apresentamos um recorte feito sobre os estudos produzidos na área da Educação Básica. Pudemos constatar que $42,55 \%$ dos estudos focam o ensino-aprendizagem de língua inglesa. A preocupação maior reside no modo como o material adotado é conduzido dentro de sala levando em conta a heterogeneidade das salas no que diz respeito ao grau de conhecimento da língua, em especial nas escolas públicas e o que preconiza o PCN de Língua Estrangeira. O segundo tema mais abordado é a avaliação com 23,40\% dos trabalhos. Estes versam sobre o processo avaliativo nas escolas públicas levando em consideração as várias realidades existentes. Temos então $14,89 \%$ das pesquisas centradas na área do desenvolvimento das habilidades, com um foco maior nas aulas de leitura e outras demonstrando preocupações com a oralidade. Em quarto lugar figuram os trabalhos sobre aquisição somando 8,51\%. De maneira geral os autores desenvolvem seus estudos focados na educação bilíngüe também tomando como base as teorias de Stephen Krashen. A seguir vêm os estudos sobre materiais didáticos adotados nas escolas. Estes representam 6,40\% dos trabalhos. A temática central é a adequação do material adotado de acordo com o que prevê o PCN de Língua Estrangeira. Temos então os estudos sobre provas de proficiência, somando 4,25\%. As dissertações discutem a preparação dos alunos do Ensino Médio de escolas particulares para exames de proficiência voltados para esta faixa etária. O objetivo principal seria a facilitação para o ingresso na universidade e, mais tarde, no campo do trabalho. Por fim temos um único estudo desenvolvido no Ensino Médio, que versa sobre a língua inglesa como ferramenta de inclusão no mundo do trabalho. 
Tabela 4 - Teses de doutorado e dissertações de mestrado produzidas no Brasil entre 1990 e 2009 sobre ensino, aprendizagem e avaliação em língua inglesa em Institutos de Idiomas.

\begin{tabular}{l|c|c}
\hline Área & Quantidade & Percentual \\
\hline $\begin{array}{l}\text { Leitura, escrita, audição } \\
\text { e fala }\end{array}$ & 8 & $34,78 \%$ \\
\hline Ensino-aprendizagem & 5 & $21,00 \%$ \\
\hline Aquisição & 3 & $13,49 \%$ \\
\hline Prática docente & 2 & $8,00 \%$ \\
\hline Avaliação & 2 & $8,00 \%$ \\
\hline Proficiência & 1 & $4,91 \%$ \\
\hline Formação de professor & 1 & $4,91 \%$ \\
\hline Inclusão & 1 & $4,91 \%$ \\
\hline Total & 23 & $100 \%$ \\
\hline
\end{tabular}

Na Tabela $n^{\circ}$ IV apresentamos um recorte feito sobre os estudos produzidos em Institutos de Idiomas. Em primeiro lugar estão os trabalhos voltados para o desenvolvimento das habilidades com $34,78 \%$. As discussões giram em torno do desenvolvimento da leitura e da escrita, bem como nas técnicas de correção utilizadas em sala para o aprendizado destas habilidades. Temos então os trabalhos focados no ensino-aprendizagem somando $21 \%$. As pesquisas versam sobre a relação aluno-professor e as diferenças entre aulas com professores falantes nativos e não-nativos de língua inglesa e as estratégias de ensino utilizadas por estes. A seguir vêm os estudos sobre aquisição com 13,49\% dos estudos. Nesta temática os trabalhos centram suas discussões em correções, práticas cooperativas e aquisição vocabular voltada para o uso de um tópico específico da língua. Em quarto lugar figuram os trabalhos sobre prática docente com um total de $8 \%$. A preocupação dos autores reside nas crenças a respeito da prática pedagógica em língua estrangeira e nas técnicas de correção utilizadas em sala com vistas à aquisição do idioma. Os estudos sobre avaliação somam também 8\% e versam sobre as diferentes práticas avaliativas utilizadas nos Institutos de Idiomas. Somando igualmente $4,91 \%$ dos trabalhos, estão as pesquisas sobre exames de proficiência com foco na escrita, formação de professores visando a noção de consciência lingüística que devem ter estes profissionais e a aprendizagem de língua inglesa como ferramenta de inclusão no mercado do trabalho.

Tabela 5 - Teses de doutorado e dissertações de mestrado produzidas no Brasil entre 1990 e 2009 sobre ensino, aprendizagem e avaliação em língua inglesa com softwares.

\begin{tabular}{l|c|c}
\hline Área & Quantidade & Percentual \\
\hline Ensino -aprendizagem & 6 & 31,57 \\
\hline $\begin{array}{l}\text { Leitura, escrita, audição } \\
\text { e fala }\end{array}$ & 5 & 26,32 \\
\hline Avaliação & 3 & 15,79 \\
\hline Formação de Professor & 2 & 10,53 \\
\hline Inglês Instrumental & 2 & 10,53 \\
\hline Inclusão & 1 & 5,26 \\
\hline Total & 19 & 100 \\
\hline
\end{tabular}

Em virtude da era tecnológica em que estamos vivendo, pudemos perceber uma produção considerável no que tange a estudos ligados a aprendizagem de língua inglesa por meio de softwares e uso da internet com um total de $31,57 \%$. A preocupação dos autores é com a interação virtual entre professores e alunos e a qualidade do material ligada à eficiência do curso oferecido. Nas pesquisas feitas sobre o desenvolvimento das habilidades, que somam $26,32 \%$, pudemos perceber um foco maior na leitura e escrita em língua inglesa. Os trabalhos sobre avaliação, 15,79\%, demonstram certa preocupação tanto com a qualidade dos cursos oferecidos, bem como as estratégias avaliativas utilizadas pelos sites e pelas mídias. Há também alguma preocupação com relação à formação 
de professores mediada por cursos on-line 10,53\%. Os ganhos na área lingüística e tecnológica. Os cursos de Inglês Instrumental somam também 10,53\% e focam no ensino de inglês para negócios e informática. E por fim um único estudo que pesquisa o uso da internet para a aprendizagem de um idioma por pessoas surdas como forma de inclusão social e digital. No que tange à produção científica sobre inglês para aviação, ao analisarmos a Tabela I, podemos ver que apenas 4, 34\% dos estudos estão voltados para esta área específica, totalizando sete estudos em nível de pós-graduação strictu senso.

Na Tabela VI podemos visualizar esses sete trabalhos enquadrados em três categorias, englobando um maior numero de teses sobre inglês para pilotos e tripulação, com três estudos produzidos, dois estudos sobre estudo de vocabulário instrumental e outros dois sobre compreensão de manuais técnicos.

Tabela 6 - Teses de doutorado e dissertações de mestrado produzidas no Brasil entre 1990 e 2009 sobre ensino, aprendizagem e avaliação em língua inglesa - inglês para aviação.

\begin{tabular}{l|c|c}
\hline Área & Quantidade & Percentual \\
\hline $\begin{array}{l}\text { Estudos de Vocabulário } \\
\text { Instrumental }\end{array}$ & 2 & $28,57 \%$ \\
\hline $\begin{array}{l}\text { Inglês para pilotos e } \\
\text { tripulação }\end{array}$ & 3 & $42,86 \%$ \\
\hline $\begin{array}{l}\text { Manuais técnicos de } \\
\text { aviação }\end{array}$ & 2 & $28,57 \%$ \\
\hline Total & 7 & $100 \%$ \\
\hline
\end{tabular}

O recorte feito na tabela VI diz respeito ao foco deste artigo que é o inglês para aviação. Ao analisarmos este quadro podemos perceber a preocupação dos autores com a aprendizagem da língua inglesa para pilotos e tripulação, 42,86 do total. Os trabalhos evocam a necessidade de uma real compreensão da língua inglesa para reduzir as chances de acidentes aéreos provocadas pela falha na compreensão e na comunicação. Os autores são unânimes quanto à carência de pesquisas nesta área e também de materiais específicos para o ensino desta linguagem especializada para que a fluência nas quatro habilidades seja alcançada.

Como se pode verificar, $28,57 \%$ dos trabalhos estão voltados para o estudo do inglês de aviação analisando o uso do vocabulário específico em situações específicas ou mesmo generalizadas. Com um mesmo percentual, identificamos trabalhos focados em manuais técnicos de aviação, cuja preocupação dos autores é a proficiência em leitura da língua inglesa para a compreensão dos manuais por parte de pilotos e mecânicos, os quais devem ter autonomia para lidar com os dados ali contidos e evitar qualquer falha na manutenção e/ou execução de tarefas, também com vistas à diminuição de risco de acidentes aeronáuticos.

A tabela VII apresenta uma síntese dos sete estudos localizados no qual retratamos dados importantes como título do trabalho, universidade em que foi defendida, a área do conhecimento, nomes dos autores e orientadores.

Ao examinarmos o referido quadro, em relação às instituições ou empresas que serviram como cenário e referencia para a realização dos sete estudos, podemos afirmar que nenhum deles tomou como referência a Academia da Força Aérea - único centro formador de pilotos militares em nosso país. Ao buscarmos informações nos resumos disponíveis no Banco de Dados pudemos verificar que estes trabalhos também não tomaram como referência alguma empresa aérea em particular. Os trabalhos versam sobre necessidades de compreensão da língua inglesa e suas particularidades na área de aviação para uma comunicação eficiente e conhecimento dos termos específicos da 
área. Podemos constatar que a preocupação não é apenas por parte da fluência dos pilotos, mas de toda a tripulação. A compreensão da língua, quer seja oralmente ou por meio da leitura e compreensão de manuais, se faz presente nestes estudos.

Tabela 7 - Referências completas das teses de doutorado e dissertações de mestrado produzidas no Brasil entre 1990 e 2009 sobre avaliação de ensino de inglês na área da aviação

\begin{tabular}{|c|c|c|c|c|}
\hline Título / Ano / Páginas & Área do Conhecimento & Universidade & Orientador & AUTOR \\
\hline $\begin{array}{l}\text { Descrição das unidades especializadas } \\
\text { poliléxicas nominais no âmbito da } \\
\text { aviação: subsídios para o ensino de } \\
\text { ESP, 2008, 230p. }\end{array}$ & Letras & UFRGS & $\begin{array}{l}\text { Maria da Graça } \\
\text { Krieger }\end{array}$ & $\begin{array}{l}\text { BOCORNY, Ana Eliza } \\
\text { Pereira }\end{array}$ \\
\hline $\begin{array}{l}\text { O uso dos verbos modais em manuais } \\
\text { de aviação em inglês: um estudo } \\
\text { baseado em corpus, 2008, p. } 283\end{array}$ & Letras & UFRGS & $\begin{array}{l}\text { Maria da Graça } \\
\text { Krieger }\end{array}$ & SARMENTO, Simone \\
\hline $\begin{array}{l}\text { Comunicações entre pilotos e } \\
\text { controladores de voo: fatores } \\
\text { lingüísticos, discursivo-interacionais e } \\
\text { interculturais, 2009, p. } 381\end{array}$ & $\begin{array}{l}\text { Linguística aplicada, } \\
\text { Letras e Artes }\end{array}$ & UFRJ & $\begin{array}{l}\text { Aurora Maria } \\
\text { Soares Neiva }\end{array}$ & $\begin{array}{l}\text { MONTEIRO, Ana Lúcia } \\
\text { Tavares }\end{array}$ \\
\hline $\begin{array}{l}\text { Para a elaboração de um vocabulário } \\
\text { especializado bilíngüe (inglês/ } \\
\text { português) da linguagem de aviação, } \\
\text { 1995, p. } 380\end{array}$ & Lingüística & USP & $\begin{array}{l}\text { Maria Aparecida } \\
\text { Barbosa }\end{array}$ & $\begin{array}{l}\text { MARINOTTO, } \\
\text { Demóstene }\end{array}$ \\
\hline $\begin{array}{l}\text { Dicionário técnico bilíngüe inglês- } \\
\text { português na subárea do check-list, } \\
\text { 2009, p. } 215\end{array}$ & Lingüística & USP & $\begin{array}{l}\text { Maria Aparecida } \\
\text { Barbosa }\end{array}$ & $\begin{array}{l}\text { SILVA, Eloíza Terezinha } \\
\text { Fernandes }\end{array}$ \\
\hline $\begin{array}{l}\text { Inglês instrumental para comissários } \\
\text { de voo: análise de necessidades, 2003, } \\
\text { p. } 120\end{array}$ & $\begin{array}{l}\text { Lingüística aplicada, } \\
\text { estudos da linguagem }\end{array}$ & PUC-SP & Leila Barbara & $\begin{array}{l}\text { ANDRADE, Renata } \\
\text { Ribeiro }\end{array}$ \\
\hline $\begin{array}{l}\text { Inglês para pilotos: análise de } \\
\text { necessidades das situações-alvo, } \\
2006 \text {, p.130 }\end{array}$ & Lingüística & PUC-SP & Leila Barbara & $\begin{array}{l}\text { GALLO, Cybele } \\
\text { Aparecida D’Ávila }\end{array}$ \\
\hline
\end{tabular}

Ao explorarmos os trabalhos citados pudemos perceber que há realmente uma carência de estudos na área de aprendizagem da língua inglesa com todos os envolvidos no processo de voo, dos pilotos aos controladores passando pelos mecânicos e comissários de voo. Também são pontuados outros aspectos particulares da língua como utilização de determinadas formas verbais ou descrições do léxico específico do inglês utilizado em aviação (BOCORNI 2008; SARMENTO 2008; GALLO 2006). Existem propostas de dicionários específicos para a área de aviação e a elaboração de vocabulários especializados (SILVA 2009; MARINOTTO
1995). Há uma única dissertação que mostra a necessidade da proficiência em língua inglesa e a fluência necessária para pilotos e controladores de vôo. Esta dissertação busca "investigar possíveis ameaças à compreensão oral relativas ao uso da língua inglesa por parte de pilotos e controladores brasileiros num contexto multicultural." (MONTEIRO, 2009). Também única é a dissertação de Andrade (2003) no que tange à necessidade da fluência em língua inglesa por comissários de vôo em situações particulares desta profissão.

Aoolharmoscomcertocuidado, podemos verificar que as pesquisas desenvolveram-se, 
quase totalmente, a partir de 2003 com uma concentração maior a partir de 2006, quando o Brasil enfrentou o primeiro caos aéreo e com o acidente ocorrido entre um Legacy e um Boeing 737 que se chocaram a 37 mil pés de altura, como já foi mencionado anteriormente. Ao analisarmos os trabalhos percebemos claramente a preocupação crescente com a necessidade da fluência como fator de segurança de vôo e também a necessidade de mais pesquisas sobre o assunto.

\section{Conclusões}

Este artigo teve como objetivo levantar uma discussão teórica sobre as abordagens de ensino de língua estrangeira e a seguir traçar o estado da questão do ensino de língua inglesa com foco na grande área de ensino e avaliação e, em seguida, mais especificamente em estudos sobre inglês para a aviação. Pudemos averiguar que a temática 'ensino de inglês na área de aviação', no momento, ainda conta com poucos estudos preocupados com a língua inglesa como fator de segurança de vôo. Contudo, pode-se afirmar que é uma área emergente, a partir da produção científica realizada na metade da primeira década de 2000.

Nosso trabalho, assim como outros na área da aviação, tem uma grande preocupação com a formação em língua inglesa para pilotos. Como observamos na Tabela VII, as áreas de concentração são a linguística e a linguística aplicada, áreas de estudo ocupadas com tudo o que se relaciona à comunicação, cuja preocupação maior é com o desenvolvimento da linguagem em cada uma das suas áreas específicas, com o nível de fluência necessária avaliado durante todo o processo de aprendizagem. Ao perpassarmos o ensino de línguas estrangeiras, pudemos encontrar as muitas modalidades que foram desenvolvidas no decorrer do tempo, e todas buscam uma maior eficiência na habilidade do uso da língua. A excelência em fluência é o ponto em comum. Seja nos primeiros métodos, seja nos últimos, os autores sempre buscam novas formas de se aprender um idioma. Ao focarmos nossa atenção no uso da língua inglesa por tripulações e controladores de voo o que buscamos foi traçar o estado da questão de trabalhos na área de inglês para aviação. Aqui pudemos verificar que, ao longo de 19 anos, apenas sete trabalhos foram desenvolvidos sobre o assunto. Apesar de ser uma área que ainda apresenta uma produtividade um pouco reduzida, podemos, talvez, concluir que, este é um campo ainda em construção, e que a preocupação da comunidade acadêmica com a segurança de voo está crescendo em nosso país. Tripulação e controladores de voo têm que possuir um conhecimento cada vez mais profundo sobre a língua utilizada, não apenas pelas exigências de uma área de trabalho, mas por uma questão de segurança nacional.

\section{Referências}

ANDRADE, R. R. Inglês instrumental para comissários de voo: análise de necessidades. 2003. 120f. Dissertação (Mestrado em Linguística Aplicada) Pontifícia Universidade Católica de São Paulo, São Paulo, São Paulo, 2003.

BOBITT, J. F.. O currículo. 1. Ed. Porto: Didáctica Editora, 2004.

BOCORNY, A. E. P. Descrição das unidades especializadas poliléxicas nominais no âmbito da aviação: subsídios para o ensino de ESP. 2008. 230f. Tese (Doutorado em Linguística Aplicada) - Universidade Federal do Rio Grande do Sul, Porto Alegre, Rio Grande do Sul, 2008. 
BRASIL. Manual de procedimentos 061002/SSO - verificação do cumprimento dos requisitos de proficiência linguística de pilotos de transporte aéreo e da aviação geral Brasília - DF: Agencia Nacional de Aviação Civil, 2009.

CHAGAS, R. V. C. Didática especial de línguas modernas. 3. ed. São Paulo: Companhia Editora Nacional, 1957.

CHOMSKY, N. Language and mind. 3. ed. New York: Cambridge University Press, 2006.

ESTADÃO.COM.BR Relembre os piores acidentes aéreos desde a década de 70 . Disponível em: <http://www.estadao.com. br/noticias/internacional,relembre-ospiores-acidentes-aereos-desde-a-decadade-70/> Acesso em: 18 de agosto de 2010

FOLHA.COM - Cotidiano - Homem que estava no Legacy que derrubou voo $1907 \mathrm{diz}$ que pode ter ocorrido erro de interpretação. Disponível em: <http://www1.folha.uol. com.br/cotidiano/> Acesso em 18 de agosto de 2010.

GALLO, C. A. D. Inglês para pilotos: análise de necessidades das situaçõesalvo. 2006. 130f. Dissertação (Mestrado em Linguística) - Pontifícia Universidade Católica de São Paulo, São Paulo, São Paulo, 2006.

LUCKESI, C. C. Avaliação da aprendizagem escolar. 4. ed. São Paulo: Cortez, 1999.

MARINOTTO, D. Para a elaboração de um vocabulário especializado bilíngue (inglês/português) da linguagem de aviação. 1995. 380f. Tese (Doutorado em Linguística) - Universidade de São Paulo, São Paulo, São Paulo, 1995.

MONTEIRO, A. L. T. Comunicação entre pilotos e controladores de voo: fatores lingüísticos, discursivo-interacionais e interculturais. 2009. 381f. Dissertação (Mestrado em Linguística,Letras e Artes). Universidade Federal do Rio de Janeiro, Rio de Janeiro - RJ, 2009.

RICHARDS, J. C. \& R. T. S. Approaches and methods in language teaching: a description and analysis. Cambridge: Cambridge University Press, 1986.

SACRISTÁN, J. G. O currículo: uma reflexão sobre a prática. 3. ed. Porto Alegre: Artmed, 2000.

SARMENTO, S. O uso dos verbos modais em manuais de aviação em inglês: um estudo baseado no corpus. 2008. 283f. Tese (Doutorado em Linguística Aplicada), Universidade Federal do Rio Grande do Sul, Porto Alegre, Rio Grande do Sul, 2008.

SILVA, Eloísa T. F. Dicionário técnico bilíngue inglês-português da subárea de check-list. 2009 215f. Dissertação (Mestrado em Linguística) - Universidade de São Paulo, São Paulo, São Paulo, 2009.

STERN, H. H. Issues and options in language teaching. 3. ed. Oxford: Oxford University Press, 1996.

THERRIEN, J.; NÓBREGA-THERRIEN, S. Os trabalhos científicos e o estado da questão: reflexões teórico-metodológicas. São Paulo, Estudos em Avaliação Educacional, v. 15, n 30, jul.- dez. 2004.

TRALDI, L. L. Currículo. 3. ed. São Paulo: Atlas, 1984.

TYLER, R. W. Princípios básicos de currículo e ensino. Porto Alegre: Globo, 1974.

Enviado em: 12/09/2011 Aceito em: 23/11/2011 